\title{
REFLEXOS DA SUSTENTABILIDADE E DA SOLIDARIEDADE AMBIENTAL: DESENVOLVIMENTO E SOBERANIA ESTATAL EM JOGO
}

\section{EFFECTS OF SUSTAINABILITY AND ENVIRONMENTAL SOLIDARITY: DEVELOPMENT AND STATE SOVEREIGNTY AT STAKE}

\author{
${ }^{1}$ Artur Amaral Gomes
}

\section{RESUMO}

A crise ecológica é uma problemática que assola todo o planeta, razão pela qual evidencia a existência de uma espécie de solidariedade que não pode ser afastada, a solidariedade ambiental. Como consequência desta, é evidente que o passo inicial para o lançamento de quaisquer diretrizes ambientais é o estabelecimento de uma cooperação internacional entre estados. O princípio da sustentabilidade é um desses guias, encontrando lugar hoje em todos os ordenamentos jurídicos que demonstram uma mínima preocupação com o meio ambiente. A partir do manejo do método de pesquisa bibliográfica, o presente artigo pretende demonstrar como a necessidade de amparo do meio ambiente é o suficiente para legitimar os reflexos da sustentabilidade e da solidariedade ambiental sobre os conceitos de soberania estatal e de desenvolvimento na atualidade.

Palavras-chave: Sustentabilidade, Solidariedade, Soberania, Desenvolvimento sustentável, Meio ambiente

\begin{abstract}
The ecological crisis is a problem that plagues the entire planet, which shows the existence of a kind of solidarity that can not be ruled out, the environmental solidarity. As a result of this, it is clear that the first step towards the foundation of any environmental guidelines is the establishment of an international cooperation between states. The principle of sustainability is one of these guidelines, finding place today in all jurisdictions that demonstrate a minimal concern for the environment. From the handling of the bibliographic research method, this article aims to demonstrate that the need for protection of the environment is enough to legitimate the effects of sustainability and environmental solidarity on the concepts of state sovereignty and development today.
\end{abstract}

Keywords: Sustainability, Solidarity, Sovereignty, Sustainable development, Environment

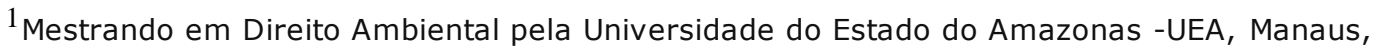
Amazonas. Estagiário no Tribunal de Justiça do Amazonas, (Brasil) email: tutortreinamento@gmail.com
} 


\section{INTRODUÇÃO}

Explicitada pelos fenômenos característicos de mudanças climáticas, pelas tragédias naturais, pela crescente facilidade de exposição de situações de degradação e pela "recente" preocupação com a finitude dos recursos naturais, a crise ecológica global e seus efeitos contínuos e cumulativos demandam dos Estados comportamentos e ações que demonstrem a preocupação destes com o previsível e infeliz resultado final da crise, assim como a ambição de afastá-lo de sua concretização. A fim de garantir a eficácia de tais atitudes, cada Estado deve agir de forma individual no âmbito interno de seu território, no "seu" meio ambiente, assim como no âmbito externo, ou internacional, porém de maneira conjunta com os demais Estados, ou pelo menos todos aqueles que entendem a consequência do existir em um mesmo planeta em crise.

A formação de organizações e comitês, assim como a participação em conferências e encontros que partilham da inquietação ambiental, são ações que demonstram como os Estados passaram a entender a necessidade de que, apesar da distância física, é imprescindível compreender a ideia de que cada um faz parte de um todo incontestável. Toda e qualquer violação irrazoável do meio ambiente, ocorrida em qualquer parte do globo, gera sequelas que necessariamente serão sentidas em todo o planeta. Apesar de ser difícil argumentar pela existência de uma solidariedade em nível social e político entre todos os Estados, não é possível negar que existe uma solidariedade ambiental da qual nenhum Estado consegue escapar, e este é o "sentimento" que fundamenta as supracitadas reuniões e associações.

Antes da preocupação com o meio ambiente ganhar evidência, ela mal era considerada uma preocupação. O desenvolvimento, seja em qual seara, era a prioridade dos Estados em uma corrida desmedida por status e por poder, estes medidos a partir da soma de "riquezas" que cada nação possuía, e possui, controle sobre. A industrialização, a modernização, a pavimentação, a evolução da tecnologia, a substituição do natural pelo descartável, pelo tóxico e pelo artificial foram prioridades durante muito tempo e, de certa forma, ainda não deixaram de ser. Sim, o meio ambiente passou a ser uma prioridade mundial, mas, no lugar de superar as prioridades do passado, situa-se no mesmo patamar que estas, e mesmo que tal situação seja negada, não é difícil enxergar que esta é a realidade.

Harmonização, conciliação, combinação ou ajustamento. Não importa o sinônimo, é evidente que o objetivo de muitas reuniões internacionais, como é possível verificar a partir 
dos documentos provenientes destas, é criar termos, ideologias, princípios, técnicas e formas de harmonizar as prioridades do passado, e do presente, com a proteção e manutenção do meio ambiente. Destaca-se aqui o princípio da sustentabilidade, verdadeira "ideologia" que já se espalhou pelo ordenamento jurídico de muitas nações, harmonizando cada Direito com os seus mandamentos. A sustentabilidade é como o ar que preenche o "vazio" de um invólucro não repleto pelo conteúdo que deve guardar, sendo o invólucro aqui cada ordenamento e o conteúdo as suas normas legais, com uma diferença: o "direito" ao adquirir a qualidade de sustentável passa a gozar de novas limitações, estas voltadas para o bem do meio ambiente.

A ideia de desenvolvimento sustentável, já disseminada de forma enfadonha, e bem delineada, mesmo que não expressamente, na Constituição Brasileira de 1988, é o suficiente para mostrar como os Estados exercem hoje uma constante atividade de harmonização entre o seu próprio desenvolvimento, sobretudo o econômico, com a necessária conservação do meio ambiente, ou pelo menos com a atenuação de suas violações. Como dito antes, todo problema de caráter global precisa ser encarado de forma interestadual e de forma isolada, mas, é óbvio que toda medida isolada é também uma consequência de compromissos firmados na esfera internacional. A ausência de uma solidariedade social e política gera esse efeito, tal ausência chega a ter a mesma relevância que a existência da solidariedade ambiental.

Submeter-se a restrições e princípios que objetivam a proteção do meio ambiente geram efeitos que dialogam com características e direitos específicos de cada Estado, não importando, necessariamente, se tais submissões encontram-se traduzidas em leis nacionais ou internacionais, desde que se compreenda que sua origem se dá a partir de negociações internacionais. É ainda cabível se falar em soberania estatal absoluta e em "livre" direito do desenvolvimento para os Estados que passam a obedecer a regras e princípios estabelecidos internacionalmente, mesmo que oriundos da inexorável solidariedade ambiental?

Tomando como ponto de partida o princípio da sustentabilidade e a tentativa de conciliação da proteção do meio ambiente com o desenvolvimento, sobretudo por meio de imposições legais, o presente artigo almeja identificar como a solidariedade ambiental afeta a soberania e o desenvolvimento de um Estado quando este age, ou, ao menos aparenta agir, de forma a contribuir eficazmente para a amenização da crise ecológica global.

\section{SUSTENTABILIDADE E DESENVOLVIMENTO}


Após determinar que a crise ecológica atual teve como origem a propagação humana por todos os cantos do planeta, o que acarretou a quebra da pátria planetária e a formação de inúmeras nações, cada uma com uma necessidade própria e latente pelo desenvolvimento, Edgar Morin (2003, p. 69) aponta que o processo de resolução da crise deve se dar a partir do fortalecimento de uma consciência ecológica, ou seja, "a tomada de consciência do problema global e do perigo global que ameaçam o planeta”. O princípio da sustentabilidade e a forma como este tem se fortificado em todos os ordenamentos jurídicos do planeta denota justamente o fortalecimento proposto por Morin.

Segundo Klaus Bosselmann (2015, p. 18), "salta aos olhos que nossa sobrevivência depende da habilidade de manter e respeitar a integridade ecológica da Terra. Essa é a ideia principal do princípio da sustentabilidade”. Luís Paulo Sirvinskas (2015, p. 144) define como finalidade de tal princípio a busca pela compatibilização do atendimento das necessidades sociais e econômicas do homem com a necessidade de preservação do meio ambiente, assegurando, assim, a subsistência de todas as formas de vida na Terra, incluindo a humana. $\mathrm{O}$ autor ainda complementa que a sustentabilidade prega pelo respeito da capacidade de suporte do meio ambiente quando das tentativas de melhora na qualidade de vida, ou seja, o declínio de fatores como a pobreza e a exclusão social e econômica deve vir acompanhar a diminuição da degradação do meio ambiente.

Édis Milaré (2014, p. 70) ressalta que a ideia de sustentabilidade vai além do destino da espécie humana, possuindo verdadeira conexão com o processo de perpetuação da vida em geral, sendo verdadeiro valor inflexível do mundo natural, uma vez que a sustentabilidade é inerente aos recursos naturais e constitui fundamento das "cadeias ecossistêmicas", isto é, a existência e a manutenção de determinados recursos dependem naturalmente da existência e da manutenção de outros recursos e vice-versa. No entanto, é mais fácil de compreender como tal princípio age em tais cadeias quando estas são colocadas diante das necessidades humanas. Bosselmann (2015, p. 25) explica: "na sua forma mais elementar, a sustentabilidade reflete a pura necessidade. $\mathrm{O}$ ar que respiramos, a água que bebemos, os solos que fornecem o nosso alimento são essenciais para a nossa sobrevivência". Sobre as necessidades humanas, Frederico Amado (2014) lembra que estas, em sua maioria cultivadas por um consumismo exacerbado nutrido por fornecedores de produtos e serviços, assim como pelo Estado, são ilimitadas, enquanto os recursos naturais não, uma vez que já se estabeleceu que o planeta Terra possui uma capacidade de suporte limitada. 
Tratando ainda da relação entre o princípio da sustentabilidade e as necessidades humanas, mas desta vez em um nível mais individualizado, Bosselmann (2015, p. 144) afirma que o conflito entre proteção ambiental e proteção dos direitos individuais tem se mostrado inevitável. Bosselmann (2015, p. 145) enuncia: "da perspectiva centrada na sustentabilidade, os direitos precisam ser complementados por obrigações. A mera defesa dos direitos ambientais não altera o conceito antropocêntrico dos direitos humanos". Como exemplo, o autor destaca os direitos de propriedade e a ausência de limitações ecológicas fortes o suficiente para evitar comportamentos abusivos fundamentados no antropocentrismo.

Para Paulo Machado (2014, p. 67), dois são os critérios que dão suporte ao princípio da sustentabilidade: a) todas as ações humanas precisam ser analisadas a partir das suas consequências no tempo cronológico, estudando-se o nível destes no presente e no futuro; e b) a tentativa de prever o futuro deve se concentrar em definir a continuidade de tais efeitos e a sua duração. Verifica-se, portanto, que o comportamento humano ocupa lugar de destaque quando da análise da aplicação da sustentabilidade, porém os fins de tal aplicação não são dirigidos somente ao homem. Daniel Lourenço e Fábio Oliveira (2012, p. 305) defendem que uma "sustentabilidade profunda só existe em ruptura com o paradigma antropocêntrico, tendo em conta todos os direitos envolvidos, ou seja, também os sujeitos de direito não-humanos".

Quanto ao seu caráter de princípio, Bosselmann (2015, p. 20) afirma que "a sustentabilidade tem características históricas, conceituais e éticas de um princípio jurídico", assim como a aceitação de tal caráter é capaz de conferir legitimidade a todo um sistema legal, indo além de leis ambientais específicas. Bosselmann (2015, p. 69) complementa: "o princípio da sustentabilidade pressupõe a sua validade por meio do seu longo período de utilização e de conscientização pública", isto é, o reconhecimento de sua relevância e de sua capacidade de influenciar políticas e leis, sem qualquer dificuldade criada pela sua natureza jurídica, já demonstra que o caráter de princípio é algo óbvio e que, formalmente, depende apenas de sistemas classificatórios próprios de ordenamentos nacionais e do direito internacional ambiental.

Bosselmann (2015, p. 64) ainda observa que a sustentabilidade tornou-se um guia interpretativo e comportamental, uma vez que tratados, leis e outros princípios jurídicos agora passaram a ser julgados conforme as suas diretrizes, ou seja, surgem aí os chamados "direitos sustentáveis", aqueles que conseguem acomodar entre seus fundamentos e compatibilidades a ideia de justiça ecológica. Consequentemente, é compreensível que Bosselmann (2015, p. 89) defenda a sustentabilidade como "o mais fundamental de todos os princípios fundamentais, 
embora esta fundamentalidade ainda tenha que ser reconhecida de pleno direito e de governança".

Diante de tanta aclamação, Amado (2014) prega por cautela ao chamar atenção para a possível apropriação e, consequente, distorção do princípio da sustentabilidade quando da sua utilização para simples embelezamento de discursos proferidos por governantes ou corporações que buscam apenas denominação e aparência sustentáveis, sem, de fato, alterar comportamentos concretos, como modos de produção inescrupulosos. Tal atitude de má-fé, segundo Amado (2014), já é esperada no mundo capitalista, onde as riquezas que podem ser convertidas em pecúnia são colocadas em um patamar superior ao valor intrínseco dos recursos naturais, ou seja, quando considerados também como fins e não somente como meios para outros fins, pensamento comum daqueles que prezam pelo desenvolvimento sem qualquer preocupação com seus reflexos sobre o meio ambiente.

Para Lourenço e Oliveira (2012, p. 294), a ideia mais atualizada de sustentabilidade encontra-se intimamente vinculada a necessidade de conservação dos ecossistemas diante do processo de produção corrente, visando chamar atenção para os limites da capacidade de exploração dos recursos naturais, exploração essa que sempre busca contribuir para o bem- estar do homem. Esta relação, nem sempre pacífica, entre desenvolvimento, sobretudo o econômico, e proteção do meio ambiente é o núcleo de qualquer conceito de desenvolvimento sustentável. Antes de adentrar no campo das principais conclusões doutrinárias sobre tal relação, a mesma abordagem isolada que foi conferida à sustentabilidade precisa ser conferida à figura do desenvolvimento.

Daniel Fink (2009, p. 110) define desenvolvimento como "o conjunto de atividades destinadas à satisfação das necessidades da vida, não somente no plano econômico, mas, também no político, cultural e social". Robério Nunes dos Anjos Filho (2013, p. 21) complementa: “o processo de desenvolvimento altera não só as estruturas econômicas e produtivas, mas também sociais, institucionais e políticas, significando o aumento da produção acompanhado do incremento da renda e da capacidade econômica da população." A ideia presente no pensamento destes dois autores é de que o desenvolvimento verdadeiro é aquele que vai além do campo econômico, integrando todos os demais setores da sociedade.

Anjos Filho (2013, p. 70) enxerga o desenvolvimento como um fenômeno com abrangência o suficiente para dar igual atenção para fatores como o crescimento econômico, a proteção do meio ambiente e o desenvolvimento especificamente social. A junção de todas essas facetas do fenômeno desenvolvimentista leva o autor a concluir que quando tais facetas são 
tratadas de maneira igual, como deve ser, até mesmo as liberdades individuais são fortalecidas, do que decorre um verdadeiro processo de "desenvolvimento humano". Machado (2014, p. 86), ao tratar sobre o tema, também afirma que o desenvolvimento por si só não consegue proporcionar a felicidade humana, um processo de desenvolvimento precisa ser realizado. Anjos Filho (2013, p. 71) conclui que o verdadeiro e melhor desenvolvimento perfaz um processo "amplo, o qual abarca a cadeia produtiva, a geração e distribuição de riqueza, as necessidades humanas básicas, o bem-estar social, a participação política, tendo como centro a pessoa humana".

Para Carla Negócio e Ela Castilho (2008, p. 57), existem duas correntes conflitantes quando da tentativa de definir o que é desenvolvimento, uma que limita o desenvolvimento ao crescimento econômico e outra que vai além, mais especificamente: a) a primeira corrente possui natureza quantitativa e aponta como benefícios do desenvolvimento apenas frutos financeiros, nem mesmo importando se tais frutos são usufruídos pela população em geral; e b) a segunda corrente, a mais abrangente, soma valores não econômicos ao fenômeno do desenvolvimento, preocupando-se também com a evolução do bem-estar social e da qualidade de vida da população em geral, demonstrando que o crescimento econômico por si só não é o suficiente para o mundo atual.

Outra visão bifurcada é a explanada por Morin (2003, p. 78) ao afirmar que o desenvolvimento pode ser encarado sob dois aspectos: a) como o mito global de que a industrialização garante o bem-estar social e a felicidade, reduzindo as desigualdades sociais; e b) como um fenômeno que tem o crescimento econômico como motor imprescindível e suficientemente capaz de movimentar todos os demais campos da sociedade.

A título de curiosidade, Anjos Filho (2013, p. 25) define subdesenvolvimento como a situação em que o crescimento econômico simplesmente não existe ou existe, mas acompanhado de processos e modos de produção que degradam o meio ambiente e que não acompanham o avanço da tecnologia, resultando assim em inúmeros malefícios como a concentração de riqueza nas mãos de uma minoria e outros fatores que contribuem para o agravamento de condições sociais.

A partir do que já foi exposto, é possível identificar que o aspecto econômico do desenvolvimento é o que ganha mais destaque, uma vez que a forma como se dá, assim como suas finalidades, demonstram o seu aproveitamento para o aspecto social. Fink (2009, p. 110) aponta que a produção e o consumo formam o núcleo do desenvolvimento econômico, mas 
ressalva: "ambos devem procurar atingir seus objetivos obedecendo aos contornos (regras de cumprimento) da relação jurídica que antecede o processo produtivo: não causar desequilibrio ecológico e promover a preservação do meio ambiente para as presentes e futuras gerações". Já consolidado o entendimento de que o desenvolvimento deve ir além do aspecto econômico, considerar o meio ambiente é mais um importante fator que não pode ser olvidado, Sidney Guerra e Sérgio Guerra (2014, p. 114) concluem, portanto, que "a dicotomia 'preservar o meio ambiente' e 'fomentar o desenvolvimento econômico' é solucionável se as partes procederem de forma correta sem extremismos".

Acerca do processo de compatibilização de desenvolvimento econômico e meio ambiente, Negócio e Castilho (2008, p. 58) afirmam que tal tarefa consiste em "considerar o problemas ambientais nos lindes de um processo conjunto de planejamento, atendendo-se adequadamente às exigências de ambos", isto é, a política ambiental não deve constituir um obstáculo ao desenvolvimento, mas um verdadeiro instrumento para o seu aperfeiçoamento. Negócio e Castilho (2008, p. 59) enxergam a tarefa acima definida como "condição para que o progresso se concretize em função de todos os homens e não à custa do mundo natural e da própria humanidade". Paulo Machado (2014, p. 86) acrescenta: "a integração meio ambiente e desenvolvimento não é um favor ao meio ambiente". O autor explica seu raciocínio demonstrando que, não importando qual o projeto, quando seus aspectos e efeitos ambientais não recebem a devida atenção, grandes são as chances na natureza contribuir para o seu fracasso, uma vez que não foi considerada quando da implantação dos mesmos.

Quanto ao papel do Direito nesse processo de compatibilização, Negócio e Castilho (2008, p. 63) defendem o seu papel de conciliador, de evitar que falsas colisões ganhem proporções desnecessárias, visto que meio ambiente e desenvolvimento não devem se restringir, mas se fortalecer reciprocamente, aproveitando assim da ligação que partilham. Anjos Filho (2013, p. 30) salienta que o Direito, utilizando de ideais de justiça, protege a satisfação de muitas necessidades humanas, nem todas cabíveis de definição econômica, entre elas a contribuição do meio ambiente para a dignidade humana, razão pela qual o Direito também deve prezar por um processo efetivo e inclusivo de desenvolvimento.

Frederico Amado (2014) defende ser possível alcançar uma situação em que os impactos ambientais são diminuídos e a economia continue a evoluir, desde que o Direito Econômico esteja alinhado com o Direito Ambiental, isto é, a política econômica de qualquer Estado deve preocupar-se com a realização da justiça socioambiental. Neste sentido, Fábio Nusdeo (2009, p. 146) complementa: “o conceito de desenvolvimento implica, portanto, o de 
sustentabilidade, no sentido de que em cada fase do processo são criadas condições para que ele continue a se manifestar na fase seguinte".

É possível, portanto, concluir que todo processo desenvolvimentista é sustentável, uma vez que possui intenções de ser durável. Falta apenas a substituição de seu caráter egoísta por um ecológico. Logicamente, uma vez que se cobra do Direito, o papel do Estado também é questionado, nos termos de Celso Fiorillo (2013, p. 1813): "passou-se a reclamar um papel ativo do Estado no socorro dos valores ambientais, conferindo outra noção ao conceito de desenvolvimento". Logo, o Estado deve dar suporte a um desenvolvimento que põe em prática, sobretudo no âmbito econômico, o princípio da sustentabilidade.

\section{DESENVOLVIMENTO SUSTENTÁVEL}

O desenvolvimento com sua sustentabilidade inerente voltada também para a proteção do meio ambiente leva o nome de "desenvolvimento sustentável". Branca Martins da Cruz (2009, p. 3) caracteriza o contexto de surgimento da ideia de desenvolvimento sustentável como a época em que o avanço tecnológico, responsável pela globalização, expôs de forma inegável a existência de tantos mundos diferentes em um só planeta, ou seja, expôs quão complexa é a sociedade global atual, separada pelas diferenças culturais, mas unida pelos mesmos desejos de crescimento econômico e exploração irracional dos recursos naturais, assim como pela crescente tentativa de se exonerar de responsabilidades que atravanquem o alcance de tais desejos. Cruz (2009, p. 4) finaliza: “o desenvolvimento sustentável surge-nos assim como um imperativo categórico e mostra-se indissociável de uma gestão adequada dos recursos naturais".

Ingo Wolfgang Sarlet e Tiago Fernsterseifer (2014, p. 129) enxergam o surgimento do desenvolvimento sustentável como "o estabelecimento de uma nova ordem de valores que devem conduzir a ordem econômica rumo a uma produção social e ambientalmente compatível com a dignidade de todos os integrantes da comunidade político-estatal", isto é, uma ordem em que o desenvolvimento econômico obrigatoriamente contribui para a melhoria da qualidade de vida. Para tanto, Terence Trennepohl (2010, p. 58) destaca que precisam ser “observados os princípios científicos e as leis naturais que regem a manutenção do equilibrio dos ecossistemas", visto que o básico precisa ser levado em consideração, aquilo que a própria natureza já é capaz de demonstrar. 
A partir de uma visão antropocêntrica, Guerra e Guerra (2014, p. 113) afirmam que “o princípio do desenvolvimento sustentável tem por conteúdo a manutenção das bases vitais da produção e reprodução do homem e de suas atividades, garantindo igualmente uma relação satisfatória entre os homens e destes com o seu ambiente". A finalidade de tal manutenção, segundo Guerra e Guerra (2014, p. 116), é alcançar “o uso adequado, racional e responsável dos recursos naturais para as gerações atuais e futuras", ou seja, garantir que as futuras gerações humanas possam desfrutar do meio ambiente na mesma medida, ou similar, que a geração da atualidade. Nos termos de Bosselmann (2015, p. 28), o desenvolvimento sustentável é aquele "baseado na sustentabilidade ecológica a fim de atender às necessidades das pessoas que vivem hoje e no futuro".

Bosselmann (2015, p. 77) ainda salienta que o núcleo do desenvolvimento sustentável também conta com fortes aspectos sociais e econômicos, o que em nada deveria atrapalhar suas ambições ecológicas, é justamente esta mistura que dá operacionalidade ao conceito, somente com a ajuda de instrumentos sociais e econômicos é possível preservar os sistemas ecológicos. Este aspecto integrativo é o que dá o caráter "sustentável" ao desenvolvimento.

Ainda sobre os demais aspectos do desenvolvimento sustentável, Amado (2014) destaca a acepção social do termo que consiste na justa repartição das riquezas naturais do planeta, uma vez que não é razoável clamar pela preservação antes de assegurar o acesso a tais recursos, ou seja, antes de assegurar o mínimo de dignidade humana para a população em geral. Sarlet e Fernsterseifer (2014, p. 348) afirmam que um Estado socioambiental garante necessariamente a regulação do mercado pelo Direito, ou seja, o mais interessado em consolidar a justiça, mesmo motivo que legitima a conclusão de que, nos termos de Sarlet e Fernsterseifer (2014, p. 130), “os princípios que regem o desenvolvimento ambiental e socialmente sustentável devem pautar e vincular as condutas públicas e privadas no seu trânsito pela ordem econômica", sempre com o intuito de garantir a prévia e justa distribuição de riquezas naturais.

Quanto ao tão discutido antagonismo dos termos desenvolvimento e sustentabilidade, Machado (2014, p. 70) afirma que por muito tempo se fechou os olhos para tal conflito, colocando-se de lado o interesse ambiental e destacando-se apenas os aspectos econômicos em qualquer processo de tomada de decisões. Machado (2014, p. 70) repreende tal atitude: "a harmonização dos interesses em jogo não pode ser feita ao preço da desvalorização do meio ambiente ou da desconsideração de fatores que possibilitam o equilibrio ambiental". Neste mesmo sentido, Amado (2014) defende que o desenvolvimento sustentável deve decorrer da 
ponderação casuística entre $\mathrm{o}$ direito fundamental ao desenvolvimento $\mathrm{e}$ o direito à preservação ambiental, utilizando-se para tanto o famoso princípio da proporcionalidade.

Evidenciando a sustentabilidade enquanto núcleo do desenvolvimento, Cruz (2009, p. 4) explica que o objetivo deste é criar vínculos interoperacionais que permitam a utilização de recursos naturais de forma racional e equilibrada, afastando o seu esgotamento ou danificação irreversível, de maneira a defender a perenidade de tais recursos e o seu usufruto por gerações vindouras. A constante reafirmação deste núcleo conceitual, para Bosselmann (2015, p. 20), é o que vai permitir que "o desenvolvimento sustentável se torne o paradigma global da lei e governança".

Tratando sobre a distinção entre desenvolvimento sustentável e sustentabilidade, Bosselmann (2015, p. 89) condena o uso dos termos como sinônimos e explica que o primeiro tem o segundo como fundamento, isto é, o segundo é a base da essência do primeiro. Nos termos de Bosselmann (2015, p. 27): “o desenvolvimento sustentável deve ser entendido como aplicação do princípio da sustentabilidade, e não o contrário”. Cruz (2009, p. 39) ainda alerta para a possibilidade de encarar a sustentabilidade "como uma espécie de limite, de travão necessário ao desenvolvimento, obrigando o crescimento econômico a conciliar-se com a proteção e preservação ambientais".

Focando agora na mais simples das finalidades econômicas, a obtenção de lucro, Gilvan Luiz Hansen (2012, p. 319), a partir do raciocínio de que no capitalismo o lucro é a ambição de todo e qualquer empreendimento, defende um reposicionamento de finalidades decorrente do conceito plural de desenvolvimento sustentável, onde benefícios sociais sejam consequências obrigatórias de todo empreendimento capitalista, sendo o lucro apenas mais uma consequência, desta vez mais que merecida, e não como única finalidade almejada em detrimento da manutenção do meio ambiente. Hansen (2012, p. 319) conclui: “a obtenção de lucros não pode ser justificativa para a destruição ambiental nem para o esgotamento dos recursos naturais".

Para Fink (2009, p. 111), "será sustentável o processo produtivo ou de consumo que atenda ao equilibrio ecológico e à preservação do meio ambiente", isto é, os produtores e consumidores precisam ser os primeiros a compreender o conceito de desenvolvimento sustentável para que o processo deste se dê de forma eficaz. Fink (2009, p. 114) acrescenta: "produtores e consumidores (e, por que não englobá-los todos na condição de cidadãos e agentes sociais e políticos?) devem compreender integralmente o conceito de sustentabilidade, não apenas como postulado teórico, mas como modus vivendi cotidiano e rotineiro". 
No Brasil, este raciocínio encontra-se cristalizado na Constituição Brasileira de 1988, mais especificamente em seu artigo 170, inciso VI, onde o legislador constitucional incluiu a defesa do meio ambiente como um dos princípios da ordem econômica brasileira. Fiorillo (2013) destaca a importância da previsão de tal princípio, uma vez que a delimitação de parâmetros de livre concorrência e iniciativa é necessária para evitar o desregramento do desenvolvimento econômico. Fiorillo (2013) também aponta que a previsão perfaz um acerto do legislador constitucional ao harmonizar a economia com a tentativa de amenizar a crise ecológica global, visto que a degradação ambiental é capaz de gerar um momentâneo crescimento econômico, mas um futuro e permanente declínio da capacidade econômica, concomitantemente.

Acerca da previsão constitucional do princípio do desenvolvimento sustentável, são variadas as opiniões doutrinárias. Uadi Lâmmego Bulos (2015, p. 1365) a enxerga como um claro "limite ao exercício da livre iniciativa e da livre concorrência". Paulo de Bessa Antunes (2010, p. 14) destaca o valor hierárquico de tal previsão, afirmando que resta "assentado que licitude constitucional de qualquer atividade fundada na livre iniciativa está, necessariamente, vinculada à observância do respeito ao meio ambiente". Já Fiorillo e Thaís Carmo (2009, p. 68) assinalam que tal previsão "visa à satisfação dos preceitos fundamentais descritos no art. $1^{\circ}$ da Carta Maior, destacando-se o fundamental princípio da dignidade da pessoa humana".

Quanto à correta interpretação do princípio, Fiorillo e Carmo (2009, p. 60) afirmam ser evidente o seu caráter prevencionista, ou seja, possui o intuito de impedir que atividades econômicas sejam desenvolvidas em completa dissonância da certeza da finitude dos recursos naturais. Fiorillo (2013) ainda afasta a ideia de que o princípio impede o desenvolvimento econômico com o argumento de que todo empreendimento gera alguma degradação ambiental, o princípio apenas busca amenizar ou neutralizar esta. Seguindo este mesmo pensamento, Sirvinskas (2010, p. 185) explica: "não se pode perder de vista que o Brasil precisa crescer, e sem crescimento haverá estagnação e empobrecimento geral. O poder aquisitivo cai e, consequentemente, a qualidade de vida em todos os níveis".

Sobre a forma como o desenvolvimento sustentável foi aos poucos encontrando espaço nos ordenamentos jurídicos espalhados pelo mundo, com a ajuda de certa pressão internacional, Anjos Filho (2013, p. 32) afirma que houve resistência por parte de alguns países em desenvolvimento, uma vez que suas ambições desenvolvimentistas estavam apenas começando a se concretizar. Nos termos de Anjos Filho (2013, p. 32): "os debates ficaram centrados entre a ideia de crescimento zero de um lado e o crescimento em primeiro lugar, ou a qualquer custo, de outro". Essa situação de resistência explicita como a sustentabilidade 
pode gerar descontentamentos que levam a questionamentos acerca do exercício da soberania estatal a fim de assegurar o sucesso de pretensões de desenvolvimento, o que representa verdadeiro retrocesso no processo de fortalecimento de uma consciência ecológica global idealizado por Morin como sendo o primeiro passo para a resolução da crise ambiental.

\section{SOBERANIA ESTATAL E SOLIDARIEDADE AMBIENTAL}

Presente no artigo. $1^{\circ}$, inciso I, da Constituição Brasileira de 1988 como um dos fundamentos da República, a soberania estatal basicamente pode ser traduzida como a confirmação de independência de um Estado. Para Sahid Maluf (1995, p. 29) consiste em "uma autoridade superior que não pode ser limitada por nenhum outro poder". Sirvinskas (2010, p. 157) a define como "a capacidade que tem o Estado de autogovernar-se e reger-se por si mesmo sem interferência de qualquer organismo internacional". No mesmo sentido, Marcus Acquaviva (2010, p. 51) a conceitua como "o atributo do poder do Estado que o torna independente no plano interno e interdependente no plano externo". Dalmo de Abreu Dallari (2007, p. 84) enumera duas formas de se enxergar a soberania: a) como afirmação de independência; e b) como expressão do mais elevado poder jurídico. Extrai-se dos conceitos expostos uma ideia de supremacia e absolutismo, Bulos (2015, p. 57), consequentemente, afirma que a soberania "não admite gradações. Precisamente por possuir conteúdo absoluto, é ou não é".

Segundo Hans Kelsen (1998, p. 545), "dizer que o Estado é soberano significa que a ordem jurídica nacional é uma ordem acima da qual não existe nenhuma outra". No entanto, Kelsen abre a possibilidade da ordem internacional se encontrar acima da nacional, mas desde que devidamente reconhecida pelo Estado, ou seja, aceita. Kelsen (1998, p. 546) elabora: "Após o Estado ter reconhecido o Direito internacional, esta ordem, por seu próprio conteúdo, determina a esfera e até mesmo o fundamento de validade da ordem jurídica nacional". A soberania estatal resta representada, portanto, pelo ato de reconhecimento, pelo ato de aceitar se submeter à ordem internacional.

Como se vê, é possível então enumerar limites à soberania. Maluf (1995, p. 37) explica que no âmbito interno os princípios do direito natural e os direitos de grupos particulares, reconhecidos até constitucionalmente, limitam o exercício da soberania, já no âmbito externo todos os pressupostos para o alcance de uma convivência pacífica internacional também constituem limites. Maluf (1995, p. 38) explana: "notadamente no plano internacional, a 
soberania é limitada pelos imperativos da coexistência de Estados soberanos, não podendo invadir a esfera de ação das outras soberanias”. Logo, segundo Gerson Boson (2011, p. 296), chega a ser absurdo um Estado tomar-se como absolutamente soberano, como se seu poder fosse incontestável e impenetrável. Boson (2011, p. 301) completa: "o direito internacional penetra e se faz vigente não só nos espaços ditos 'res communis', mas também nos domínios territoriais de cada Estado". Contudo, Anjos Filho (2013, p. 139) ressalva que o caráter absoluto do conceito clássico de soberania pode sim atrapalhar o sucesso de relações interestatais, explicando uma hipótese em que um argumento nada razoável de soberania ilimitada seria o suficiente para negar eficácia ao pacta sunt servanda, o que, consequentemente, causaria um caos no âmbito do direito internacional.

Passando a tratar da relação entre soberania estatal e território, Jorge Miranda (2011, p. 131) explica: "verifica-se a cumulação da soberania territorial com a supremacia territorial (posse do território): o Estado, senhor do território, exerce, de harmonia com o Direito internacional, um poder geral e efetivo sobre esse território". Consolidado o papel de senhor do território do Estado, Fiorillo e Carmo (2009, p. 55) afirmam existir um vínculo entre a soberania e o Direito ambiental brasileiro, de forma que o "nosso direito ambiental está situado dentro do nosso poder de fazer e anular leis de forma exclusiva em nosso território, organizando nossa racionalização jurídica”.

Sobre este espaço onde orbitam soberania, território, meio ambiente e direito internacional, Bosselmann (2015, p. 187) critica a negociação de responsabilidades ambientais na esfera internacional, uma vez que acaba por violar o princípio da sustentabilidade ao assegurar que a soberania dos Estados envolvidos seja validada por um "poder de escolha". Para o autor, a sustentabilidade, assim como os direitos humanos e a justiça, não é algo que pode ser negociado. Segundo Bosselmann (2015, p. 189), o argumento que legitima tais negociações tem origem no conflito entre as ideias de territorialidade nacional e indivisibilidade do meio ambiente global, devendo ser realizado um ajuste entre o primeiro, a ficção legal, e o segundo, a realidade do planeta. Bosselmann (2015, p. 192) exemplifica: “a 'exportação' de interferências ambientais para o território 'soberano' de outros estados é compensada pela 'importação' de interferências de outros estados do ambiente em seu próprio território 'soberano". Confirmando a realidade global e a inevitabilidade da partilha dos malefícios de origem ambiental, o autor expõe a fragilidade da ficção legal.

Sobre essa ficção legal equivocada, Bosselmann (2015, p. 202) afirma: “o foco na soberania territorial leva a uma dominação dos países pobres pelos ricos, dos interesses de 
hoje sobre os de amanhã e das necessidades humanas sobre as necessidades ambientais". Compreender que o ambiente nacional é parte integrante de um ambiente global é o primeiro passo para resolver tais problemáticas. Bosselmann (2015, p. 211), usando do óbvio, conclui: “a governança para a sustentabilidade requer a aceitação de que o ambiente é confiado ao Estado individual não em virtude de sua soberania ou qualquer outra forma de benefício legal, mas por força das leis da física: qualquer território existe em um ambiente global".

A partir deste pensamento, torna-se evidente a solidariedade ambiental que une todos os Estados. Paulo Henrique Portela (2014, p. 447) aponta que, segundo tal princípio, é possível afirmar que o dano ambiental não respeita fronteiras, impondo que os Estados encontrem alguma forma de agir em cooperação. Neste sentido, Bosselmann (2015, p. 216) complementa: "se aceitarmos, portanto, que a integridade dos ecossistemas da Terra não pode ser fatiada em pedaços que se encaixam em áreas dentro ou fora das fronteiras nacionais, então os estados precisam estar vinculados a um princípio universal". Esta tomada de consciência já é possível em razão dos avanços tecnológicos. J. J. Gomes Canotilho (2003, p. 90) defende que a globalização resulta em uma integração estatal que torna crítica a ideia de unidade política soberana absoluta do Estado. Marcos Augusto Maliska (2013, p. 117) partilha de tal opinião, afirmando que "a soberania estatal hoje deve ser compreendida a partir dos conceitos de abertura, cooperação e integração".

Tratando sobre a crise da soberania absoluta, Luciana Figueiredo (2011, p. 510) afirma que a "falência do modelo conceitual clássico de soberania ligado à unidade interna e fechada dos Estados reflete uma imposição da sociedade de risco atual, que, a qualquer momento, pode sofrer as consequências da incerteza ambiental". Entra em cena, segundo Maliska (2013, p. 117), o "Estado Constitucional Cooperativo, que exige estar em permanente diálogo com a comunidade internacional, buscando a cooperação e formas de regulação jurídica cada vez mais vinculantes".

Para Bosselmann (2015, p. 211), o redimensionamento do conceito de soberania, abre espaço para que a proteção do meio ambiente estabeleça limites à soberania estatal, a fim de que se alcance uma governança para a sustentabilidade, ou seja, um comportamento que demonstre que o Estado não é um simples proprietário de recursos naturais, mas sim um verdadeiro administrador e curador do meio ambiente. Bosselmann (2015, p. 211) finaliza: "o interesse em comum pode, talvez pela primeira vez na história do direito internacional, ter o controle de sua própria criação, ou seja, da soberania do Estado". 
Figueiredo (2011, p. 506) ainda enumera três características do Estado Constitucional Cooperativo, são elas: a) maior abertura em relações com outros estados das quais decorrem imposições para o seu âmbito interno; b) cartas constitucionais com previsões que facilitem a persecução internacional de tarefas conjuntas; e c) solidariedade estatal como base de qualquer atividade em conjunto que pregue pela "relativização" de fronteiras.

Intimamente vinculado à solidariedade ambiental, o "princípio das responsabilidades comuns, mas diferenciadas" merece uma breve análise, uma vez que transparece a preocupação da sociedade internacional em tratar de forma diferenciada países com níveis diferentes de desenvolvimento. Presente no texto da Declaração de Estocolmo de 1972, assim como na Declaração do Rio de 1992, tal princípio, segundo Portela (2014, p. 449), defende a ideia de que "todos os Estados deverão contribuir para a proteção da melhoria do meio ambiente no mundo, mas na proporção de suas responsabilidades na degradação ambiental e dos meios de que dispõem para combater os problemas ambientais". Figueiredo (2011, p.

512) completa: "reconhecida igualdade jurídica dos Estados, reconhece-se também a desigualdade de fato, o que acarreta a aplicação diferenciada das regras internacionais em relação aos Estados menos desenvolvidos".

Impossível não enxergar a relação entre o "princípio das responsabilidades comuns, mas diferenciadas" e o Direito Internacional ao Desenvolvimento abordado por Anjos Filho (2013, p. 84). O autor defende que este último deve considerar a hipossuficiência dos países subdesenvolvidos, a fim de possibilitar que tais países possam reduzir suas dificuldades econômicas e sociais. No entanto, é difícil considerar tal princípio como bem sucedido, uma vez que países subdesenvolvidos ou em desenvolvimento, a fim de alcançar o status de países desenvolvidos, precisam necessariamente usar do meio ambiente para tanto, causando assim baixas na manutenção da perenidade dos recursos naturais. Qualquer tentativa na atualidade de sair do status de "em desenvolvimento" acaba sendo vista com olhar de reprovação pela sociedade internacional, uma vez que, mesmo que se tente observar os mandamentos do princípio da sustentabilidade ecológica, estes acabam sendo violados. De certa forma, tal hipótese possui ares de injustiça, visto que no passado as mesmas ações foram perpetradas por nações hoje consideradas desenvolvidas. Trata-se de um princípio falho.

Os mesmos argumentos ambientais que justificam a solidariedade ambiental são os que retiram qualquer eficácia do "princípio das responsabilidades comuns, mas diferenciadas", visto que a regra na atualidade é enxergar o meio ambiente em escala global e 
não mais isolada por estado. Bosselmann (2015, p. 188) reforça: “os territórios nacionais são parte do ambiente global e, portanto, limitados em uso e exploração”. Já Portela (2014, p. 447) destaca que "uma das mais evidentes características das questões ambientais é a grande capacidade de que problemas no meio ambiente ocorridos em um país gerem desdobramentos em outras partes do mundo ou, inclusive, em escala global".

Outro importante fator ambiental que precisa ser considerado é a incerteza do futuro. Luciana Figueiredo (2011, p. 519) proclama: "meio ambiente remete à incerteza e assim deve ser tratado". Milaré (2014, p. 79) defende atitudes prevencionistas dos Estados e justifica: "a carestia aumenta progressivamente e, num futuro (talvez não muito remoto) o poder do Estado seja invocado para contornar crises extremas". Bosselmann (2015, p. 130) utiliza do argumento da incerteza para declarar como razoável o dever de conservar os recursos naturais de modo a possibilitar que sejam utilizados por gerações futuras, uma vez que hoje ainda não é possível prever com certeza as necessidades do futuro.

Sirvinskas (2015, p. 144) defende que algum viés ambiental deve estar presente em toda e qualquer decisão, ou seja, como parte integrante e não como parte a ser compatibilizada ou conciliada, e isso deve passar a ser exercido em escala global. Bosselmann (2015, p. 21) vê o meio ambiente como o "maior unificador da humanidade, ao menos no senso de uma preocupação compartilhada". Essa é a base da ideia de solidariedade ambiental, aquela da qual não se pode escapar. Uma vez que todos os seres humanos vivem em um mesmo planeta, a crise ecológica que afeta este também afeta aqueles, é inevitável. Este é o entendimento de Morin (2003, p. 178) ao concluir: "Assumir a cidadania terrestre é assumir nossa comunidade de destino".

\section{CONCLUSÃO}

A consciência de que todos os territórios nacionais espalhados pelo mundo são interligados resta sedimentada como ponto de partida e pressuposto de eficácia de todas as medidas protetivas do meio ambiente, uma vez que tudo aquilo que ocorre isoladamente pelo planeta é sentido por este em um nível global. O desmatamento e as queimadas na América do Sul, o derretimento das geleiras dos polos do planeta, assim como muitos outros fenômenos que evidenciam a desídia no tratamento do meio ambiente são fenômenos interdependentes, ou seja, cada um pode ser considerado como causa e consequência do outro. Esta é a ideia central da consideração em escala global do meio ambiente. 
Também é evidente o status de crise ecológica que assola o planeta na atualidade. Após um longo período em que a busca desenfreada pelo desenvolvimento controlou todos os movimentos das nações, olvidada qualquer medida protetiva ambiental, o que apresenta um verdadeiro paradoxo, visto que os próprios recursos naturais foram e são os combustíveis de tal desenvolvimento, foi inevitável a chegada do momento em que o próprio meio ambiente passou a sinalizar um desgaste que modificou e continua modificando a sua essência.

De um momento para outro, a preocupação ambiental passou a chamar atenção, uma vez que o desgaste do meio ambiente ameaçou frear o desenvolvimento por completo. Conferências e reuniões de Estados foram e continuam a ser realizadas, e nestas uma espécie de solidariedade que une os Estados ganhou notoriedade. Incapaz de ser afastada, a solidariedade ambiental decorre do pensamento de que todos os territórios são partes de um todo, sendo possível concluir que as atitudes de um Estado geram consequências em outros, e vice-versa. Com a finalidade de controlar a intensidade de tais consequências, surge o princípio da sustentabilidade. Este, quase que como um vírus, se infiltrou em ordenamentos jurídicos de todo o mundo, tanto por vontade isolada de cada Estado como por resultado da pressão internacional.

Unidas, solidariedade ambiental e sustentabilidade, criadora e criatura, forçam os Estados a entender que a palavra de ordem do momento é "cooperação". Medidas isoladas e não coordenadas não são mais suficientes para proteger o meio ambiente eficazmente. Essa estratégia de coordenação de medidas é o que possibilitou a disseminação do princípio da sustentabilidade por todo o globo, gerando efeitos que precisam ser regulados e questões que precisam ser respondidas, ambas tarefas que sobram para o Direito realizar. Uma delas diz respeito ao enfrentamento entre esse espírito de cooperação internacional e a figura da soberania estatal.

O conceito clássico de soberania estatal que prega por um poder supremo e absoluto do Estado a fim de transparecer a sua independência acaba entrando em crise, necessitando ser repensado para não bater de frente com as medidas de cooperação interestatais, evitando assim argumentos que retirem a legitimidade de tais medidas. A proteção do meio ambiente a partir da cooperação internacional é mais do que motivo suficiente para classificar como acertada a flexibilização da soberania a fim de acomodar imposições externas em âmbitos internos nacionais.

Quanto às restrições do direito de desenvolvimento, principalmente o dos Estados que ainda encontram-se "em desenvolvimento", ou seja, aqueles que não colaboraram tanto para o agravamento da crise ecológica quanto outros países hoje considerados desenvolvidos e que, 
por isso, à custa do meio ambiente, podem conferir uma melhor qualidade de vida para a sua população, fica o questionamento: é justo limitar o desenvolvimento destas nações subdesenvolvidas e que sofrem com problemas como a desigualdade social e a injusta concentração de riquezas, uma vez que o desenvolvimento pode auxiliar na amenização de tais problemáticas?

Argumentar que o desenvolvimento sustentável não tem como objetivo limitar o desenvolvimento, mas apenas conciliá-lo com o princípio da sustentabilidade, é quase como dizer que semáforos de trânsito não objetivam controlar e limitar o tráfego de veículos e pedestres, mas apenas conciliar a convivência de ambos. É óbvio que a sustentabilidade limita o desenvolvimento, mas são limitações legitimadas pela tentativa de contornar a crise ecológica. Em alguns casos pode ser injusto restringir o desenvolvimento de nações que necessitam dele, mas com a ideia de ambiente global concretizada, não é mais possível enxergar tais nações e seus territórios isoladamente, visto que é certo que os efeitos do seu intenso desenvolvimento repercutiriam em todo o globo.

Uma crise gera mudanças e clama por atitudes eficazes dos envolvidos que buscam a sua resolução. Uma crise de escala global que tem como núcleo os recursos que possibilitam a subsistência de toda uma espécie gera consequências ainda mais relevantes e que vão causar discussão e descontentamento. Encaixa-se perfeitamente nesse caso o ditado que garante que os fins justificam os meios: a flexibilização do conceito de soberania estatal e a restrição do desenvolvimento são meios controversos, mas necessários, que visam garantir a conservação do meio ambiente e, consequentemente, a perenidade dos recursos naturais. Mesmo para aqueles que não acreditam em uma salvação utópica do meio ambiente, o retardamento do fim com a utilização dos meios aqui discutidos já pode ser considerado um sucesso.

\section{REFERÊNCIAS}

ACQUAVIVA. Marcus Cláudio. Teoria geral do Estado. 3. ed. Barueri: Manole, 2010.

AMADO, Frederico Augusto Di Trindade. Direito ambiental esquematizado. 5. ed. Rio de Janeiro: Forense; São Paulo: Método, 2014.

ANJOS FILHO, Robério Nunes dos. Direito ao desenvolvimento. 1. ed. São Paulo: Saraiva, 2013. 
ANTUNES, Paulo de Bessa. Direito ambiental. 12. ed. Rio de Janeiro: Lumen Juris, 2010.

BOSON, Gerson de Britto Mello. Conceituação jurídica da soberania do Estado. In: CLÈVE, Clèmerson Merlin; BARROSO, Luís Roberto. (Org.). Direito constitucional: teoria geral do Estado. São Paulo: Revista dos Tribunais, 2011. (Coleção doutrinas essenciais; v. 2). (Edições especiais: Revista dos Tribunais 100 anos).

BOSSELMANN, Klaus. O princípio da sustentabilidade: transformando direito e governança. Tradução: Phillip Gil França. 1. ed. São Paulo: Revista dos Tribunais, 2015.

BRASIL. Constituição da República Federativa do Brasil. Brasîlia: Senado Federal, 1988.

BULOS, Uadi Lâmmego. Constituição Federal anotada. 11. ed. São Paulo: Saraiva, 2015.

CANOTILHO, José Joaquim Gomes. Direito constitucional e teoria da Constituição. 7. ed. Coimbra: Almedina, 2003.

CRUZ, Branca Martins da. Desenvolvimento sustentável e responsabilidade ambiental. In: MARQUES, José Roberto. (Org.). Sustentabilidade e temas fundamentais de direito ambiental. 1. ed. Campinas: Millennium, 2009.

DALLARI, Dalmo de Abreu. Elementos de teoria geral do Estado. 26. ed. São Paulo: Saraiva, 2007.

FIGUEIREDO, Luciana Monduzzi. O direito internacional do meio ambiente sob a perspectiva do estado constitucional cooperativo: um diálogo necessário. In: MAZZUOLI, Valerio de Oliveira. (Org.). O novo direito internacional do meio ambiente. 1. ed. Curitiba: Juruá, 2011.

FINK, Daniel R. Relação Jurídica Ambiental e Sustentabilidade. In: MARQUES, José Roberto. (Org.). Sustentabilidade e temas fundamentais de direito ambiental. 1. ed. Campinas: Millennium, 2009

FIORILLO, Celso Antonio Pacheco. Comentário ao artigo 170, VI. In: CANOTILHO, J. J. Gomes; MENDES, Gilmar Ferreira; SARLET, Ingo Wolfgang; STRECK, Lenio Luiz. (Coords.). Comentários à Constituição do Brasil. São Paulo: Saraiva/Almedina, 2013.

Curso de direito ambiental brasileiro. 14. ed. São Paulo: Saraiva, 2013.

; CARMO, Thaís Maria Leonel do. Desenvolvimento sustentável: a ordem econômica do capitalismo e a questão do meio ambiente na Constituição Federal de 1988 Art. 70, VI. In: MARQUES, José Roberto. (Org.). Sustentabilidade e temas fundamentais de direito ambiental. 1. ed. Campinas: Millennium, 2009.

GUERRA, Sidney; GUERRA, Sérgio. Curso de direito ambiental. 2. ed. São Paulo: Atlas, 2014. 
HANSEN, Gilvan Luiz. A sociedade de consumo e o paradoxo da proteção ambiental. In: FLORES, Nilton Cesar. (Org.). A sustentabilidade ambiental em suas múltiplas faces. 1. ed. Campinas: Millennium, 2012.

KELSEN, Hans. Teoria geral do direito e do estado. Tradução: Luís Carlos Borges. 3. ed. São Paulo: Martins Fontes, 1998.

LOURENÇO, Daniel Braga; OLIVEIRA, Fábio Corrêa Souza de. Sustentabilidade Insustentável. In: FLORES, Nilton Cesar. (Org.). A sustentabilidade ambiental em suas múltiplas faces. 1. ed. Campinas: Millennium, 2012.

MACHADO, Paulo Affonso Leme. Direito ambiental brasileiro. 22. ed. São Paulo: Malheiros, 2014.

MALISKA, Marcos Augusto. Comentário ao artigo 1., I. In: CANOTILHO, J. J. Gomes; MENDES, Gilmar Ferreira; SARLET, Ingo Wolfgang; STRECK, Lenio Luiz. (Coords.). Comentários à Constituição do Brasil. São Paulo: Saraiva/Almedina, 2013.

MALUF, Sahid. Teoria geral do Estado. 23. ed. São Paulo: Saraiva, 1995. MILARÉ, Édis.

Direito do ambiente. 9. ed. São Paulo: Revista dos Tribunais, 2014. MIRANDA, Jorge. Teoria do Estado e da Constituição. 3. ed. Rio de Janeiro: Forense, 2011. MORIN, Edgar; KERN,

Anne Brigitte. Terra-Pátria. Tradução: Paulo Azevedo Neves da

Silva. 4. ed. Porto Alegre: Sulina, 2003.

NEGÓCIO, Carla Daniela Leite; CASTILHO, Ela Wiecko Volkmer de. Meio Ambiente e Desenvolvimento: uma interface necessária. In: THEODORO, Suzi Huff; BATISTA, Roberto Carlos; ZANETI, Izabel. (Coords.). Direito ambiental e desenvolvimento sustentável. 1. ed. Rio de Janeiro: Lumen Juris, 2008.

NUSDEO, Fábio. Sustentabilidade. In: MARQUES, José Roberto. (Org.). Sustentabilidade e temas fundamentais de direito ambiental. 1. ed. Campinas: Millennium, 2009

PORTELA, Paulo Henrique Gonçalves. Direito internacional público e privado. 6. ed. Salvador: Juspodivm, 2014.

SARLET, Ingo Wolfgang; FERNSTERSEIFER, Tiago. Direito constitucional ambiental. 4. ed. São Paulo: Revista dos Tribunais, 2014.

SIRVINSKAS, Luís Paulo. Manual de direito ambiental. 13. ed. São Paulo: Saraiva, 2015.

Tutela constitucional do meio ambiente: interpretação e aplicação das normas constitucionais ambientais no âmbito dos direitos e garantias fundamentais. 2. ed. São Paulo: Saraiva, 2010.

TRENNEPOHL, Terence Dorneles. Manual de direito ambiental. 5. ed. São Paulo: Saraiva, 2010. 